\title{
Influence of MDM2 polymorphisms on squamous cell carcinoma susceptibility: a meta-analysis
}

\author{
This article was published in the following Dove Press journal: \\ OncoTargets and Therapy \\ II October 2016 \\ Number of times this article has been viewed
}

\section{Huanxin Yu \\ Haiyan Li \\ Jinling Zhang \\ Gang Liu}

Department of Otorhinolaryngology Head and Neck Surgery, Tianjin Huanhu Hospital, Tianjin, People's Republic of China
Correspondence: Huanxin Yu Department of Otorhinolaryngology Head and Neck Surgery, Tianjin Huanhu Hospital, 6 Jizhao Road, Jinnan, Tianjin 300350, People's Republic of China

Tel +862260367616

Fax +86226036 765I

Email yuhuanxin66@।63.com
Purpose: Controversial associations between single-nucleotide polymorphisms (rs2279744, rs937283, rs3730485) of the MDM2 gene and the etiology of squamous cell carcinomas (SCCs) have been reported. This merits further comprehensive assessment.

Materials and methods: We systematically reviewed the available data and conducted an updated meta-analysis to evaluate the genetic effect of $M D M 2$ polymorphisms in SCC susceptibility, using Stata/SE 12.0 software.

Results: After screening, 7,987 SCC cases and 12,954 controls from 26 eligible case-control studies were enrolled. Overall, compared with the control group, a significantly increased SCC risk was observed for the MDM2 rs2279744 polymorphism in the Asian population (test of association: odds ratio [OR] 1.12, $P=0.027$ for $\mathrm{G}$ vs T; OR 1.26, $P=0.016$ for GG vs TT; OR 1.25, $P<0.001$ for GG vs TT + TG; and OR 1.08, $P=0.023$ for carrier G vs T). In subgroup analysis by SCC type, a similarly increased esophageal SCC risk was detected (OR 1.19, $P<0.001$ for G vs T; OR 1.46, $P<0.001$ for GG vs TT; and OR 1.48, $P=0.005$ for GG vs TT + TG). Furthermore, MDM2-TP53 double mutation was statistically associated with increased SCC susceptibility overall (OR 1.52, $P=0.001$ ), especially in the Asian population (OR 1.49, $P=0.022$ ). However, no significant difference between the control and case groups was obtained for MDM2 rs 937283 or rs3730485 under any genetic model (all $P>0.05$ ).

Conclusion: Our results highlight a positive association between the GG genotype of MDM2 rs2279744 polymorphism and an increased risk of esophageal SCC in the Asian population, which needs to be clarified by more large-scale studies.

Keywords: MDM2, SCC, SNP, meta-analysis

\section{Introduction}

The MDM2 gene maps to chromosome 12q14.3-q15. ${ }^{1}$ The MDM2 protein forms a complex with the $\mathrm{p} 53$ protein, attenuates the activity of $\mathrm{p} 53$, and promotes the subsequent degradation of p53 by acting as a ubiquitin E3 ligase for p53.,3 The abnormal expression of the MDM2/TP53 genes is linked to carcinogenesis or malignant transformation. ${ }^{2,4,5}$ Accumulating evidence supports the link between the alteration of protein structural/functional behavior and single-nucleotide polymorphisms (SNPs) within relative genes. ${ }^{6-11}$ Multiple prediction or detection techniques, such as structural biology, computational platform, and molecular dynamic simulation, contribute to the investigation of identification and function of disease-associated SNPs. ${ }^{6-11}$ The SNPs of rs2279744 (T309G or SNP309), rs3730485 (del1518+-) and rs937283 (A2164G), have been identified in the human $M D M 2$ gene. ${ }^{12,13}$ Previous reports have shown that $M D M 2$ polymorphisms are associated with susceptibility to various clinical diseases, such as bladder cancer, ${ }^{14}$ hepatocellular carcinoma, ${ }^{15}$ myelodysplastic syndromes, ${ }^{16}$ and leukemia. ${ }^{17,18}$ 
Keratinization of the epidermal cells often leads to the occurrence of squamous cell carcinoma (SCC), which behaves as the uncontrolled growth of outer abnormal squamous cells of the epidermis. ${ }^{19-21}$ Specific types of SCC, such as head and neck SCC (HNSCC), skin squamous cell carcinoma (SSCC), esophageal SCC (ESCC), oral SCC (OSCC), lung SCC (LSCC), and cervical squamous cell carcinoma (CSCC), have been described. ${ }^{19-23}$

The different effects of the genetic mutations within $M D M 2$ have been reported to be related to the carcinogenesis of specific SCC types. For example, a lower plasma MDM2 level was observed in laryngeal SCC patients with the GT genotype of MDM2 rs2279744 than the TT genotype. ${ }^{24}$ The prevalence of MDM2 rs2279744 might be involved in OSCC onset, rather than increased OSCC risks. ${ }^{25}$ Although several previous meta-analyses on the correlation between MDM2 rs2279744 polymorphism and the risks of HNSCC, OSCC, or ESCC have been reported, ${ }^{26-28}$ another systematic evaluation with enlarged statistical power is still meaningful. Moreover, the meta-analyses of the association between MDM2 rs937283 and rs3730485 polymorphisms and SCC risks, or between the MDM2 rs2279744 polymorphism and other SCC types, such as SSCC and CSCC, have not been reported yet. It was thus worthwhile carrying out an updated systematic review and meta-analysis, in order to reassess the genetic relationship between common MDM2 polymorphisms (rs2279744, rs937283, and rs3730485) and the overall risks of SCC.

\section{Materials and methods}

\section{Article search}

We searched for potentially relevant articles (up to May 7, 2016) from seven electronic databases: PubMed, Web of Science, Cochrane, Scopus, Chinese National Knowledge Infrastructure (CNKI), Wanfang, and Weipu. The key terms were as follows: mouse double minute 2 homolog; proto-oncogene proteins c-mdm2; MDM2; MDM2 proto-oncogene, E3 ubiquitin protein ligase; human homolog of mouse double minute 2; murine double minute 2; polymorphism; mutation; SNP; single nucleotide polymorphism; T309G; rs2279744; A2164G; rs937283; del1518; rs3730485; G285C; rs117039649; squamous cell carcinoma; carcinoma, squamous cell; and SCC.

\section{Article screening and data extraction}

With the help of EndNote X7 software, potential articles were screened for eligibility according to our strict inclusion/ exclusion criteria. Exclusion criteria were duplicated articles, review or conference abstract, not human or clinical data, not relevant to MDM2, not about SCC, meta-analysis, not relevant to mutation, lack of control data, and overlapped data. Eligible case-control studies needed to be linked to SCC risks and contain data on individual genotype numbers of MDM2 rs2279744, rs937283, and rs3730485 polymorphisms.

We independently extracted the following data: first author, year of publication, country, ethnicity, SNPs, sample sizes and genotype frequencies of case/control group, SCC type, source of control, genotyping assay, $P$-values of Hardy-Weinberg equilibrium (HWE), and test of control groups. A detailed discussion was required for the conflicting assessment.

\section{Statistical analysis}

Pooled odds ratios (ORs) with 95\% confidence intervals (CIs) and $P$-values of associations based on Mantel-Haenszel statistics were calculated by Stata 12.0 software (StataCorp LP, College Station, TX, USA). $P>0.05$ was considered the exclusion of statistically significant difference between case and control groups. The $I^{2}$ test $(0 \%-100 \%)$ and $Q$-statistic were adopted to evaluate the potential heterogeneities across casecontrol studies. $P>25 \%$ or $P$-value of $Q$-statistic $<0.1$ was considered significant heterogeneity, and statistical analysis under a random-effect model and sensitivity analysis were conducted. Six genetic (allele, homozygote, heterozygote, dominant, recessive, and carrier) models were employed. Subgroup analyses by ethnicity, source of controls, HWE or SCC types were also performed. In addition, potential publication bias was assessed by analysis of Begg's funnel plots (continuity-corrected) and Egger's publication-bias plots.

\section{Results}

\section{Studies selected for meta-analysis}

Figure 1 shows a flow diagram of our article-search strategy. A total of 545 potentially relevant articles were retrieved initially from the databases: PubMed ( $\mathrm{n}=95)$, Web of Science $(n=260)$, Cochrane $(n=0)$, Scopus $(n=73)$, CNKI $(n=54)$, Wanfang $(\mathrm{N}=44)$, and Weipu ( $\mathrm{n}=19)$. A total of 378 articles were obtained after duplicates had been removed by the EndNote software, and then 336 articles were excluded by screening titles and abstracts according to the exclusion criteria. Specific information is shown in Figure 1. Next, 42 full-text articles were assessed for eligibility; 16 articles were then excluded for lack of control data $(n=10)$ and overlapped data $(n=6)$. Finally, 26 independent articles with 7,987 SCC cases and 12,954 controls were selected for our meta-analysis. ${ }^{4,12,13,18,24,25,29-48}$ We then carefully extracted the data and summarized the characteristics (Table 1). 


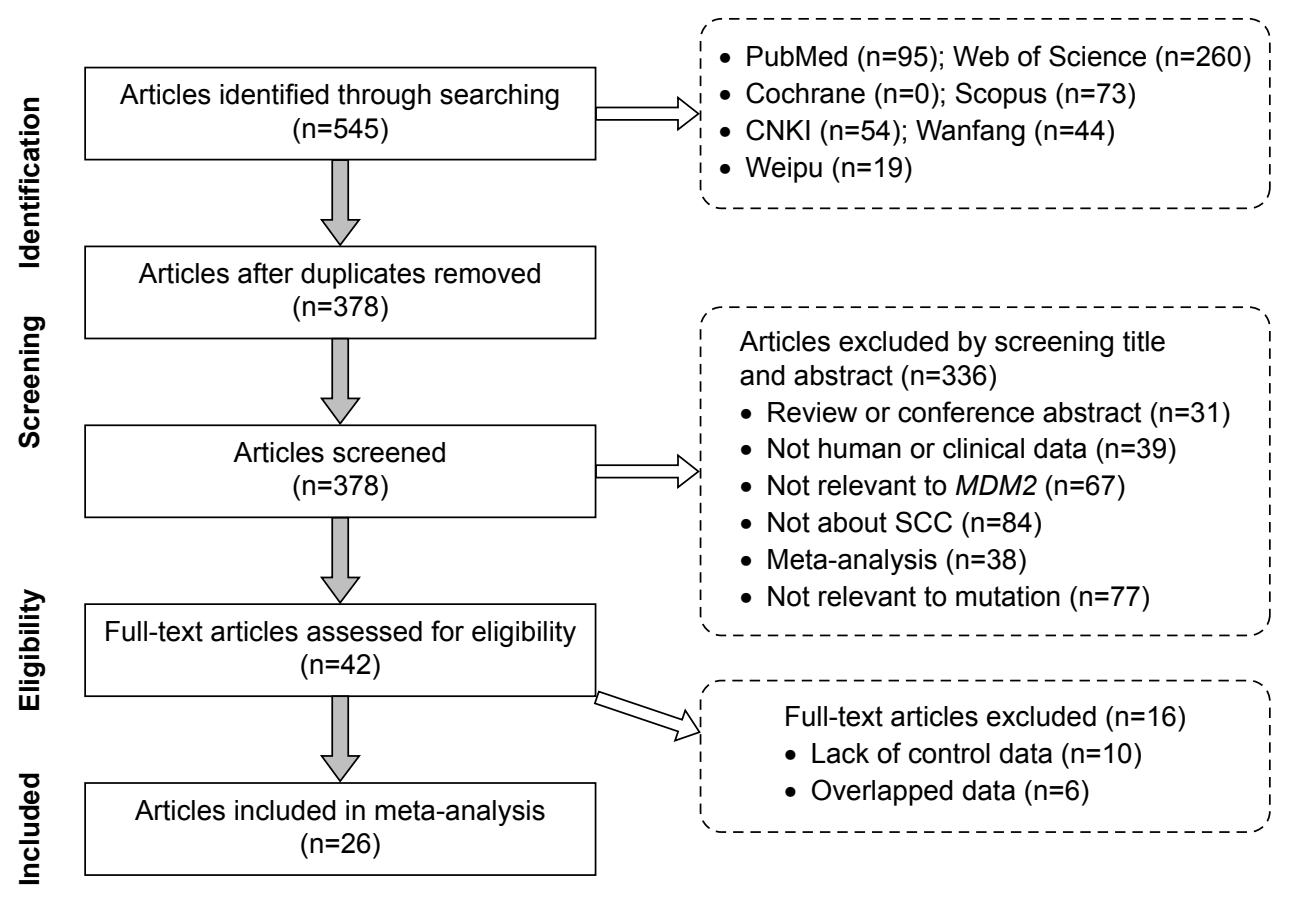

Figure I Flow diagram of article-search strategy for meta-analysis. Abbreviation: SCC, squamous cell carcinoma.

\section{Polymorphism rs2279744 of MDM2 and SCC susceptibility}

A total of 25 case-control studies ${ }^{4,12,13,18,24,25,30-48}$ were enrolled for the meta-analysis of $M D M 2$ rs 2279744 and risks of SCC. As shown in Table 2, the results (G vs T, $P=70.0 \%, P<0.001$; GG vs TT, $I^{2}=59.1 \%, P<0.001$; TG vs TT, $I^{2}=72.9 \%$, $P<0.001 ; \mathrm{TG}+\mathrm{GG}$ vs TT, $I^{2}=73.7 \%, P<0.001 ; \mathrm{GG}$ vs $\mathrm{TT}+\mathrm{TG}, I^{2}=36.3 \%, P=0.04$; carrier G vs T, $I^{2}=31.5 \%$, $P=0.068)$ suggested that between-study heterogeneity existed for $M D M 2$ rs2279744. The random-effect model was thus applied for meta-analysis. The pooled results further showed that an increased SCC risk was observed under the allele model (Table 2, G vs T, OR 1.09, 95\% CI 1-1.19; $P=0.041$ ), homozygote model (GG vs TT, OR 1.17, $95 \%$ CI $1.02-1.36 ; P=0.03$ ), and recessive model (GG vs TT + TG, OR 1.18, 95\% CI 1.07-1.30; $P=0.001)$, but not other genetic models. Forest plots can be seen for meta-analysis of the allele (Figure 2A), homozygote (Figure 3A), heterozygote (Figure 4A), dominant (Figure 5A), and recessive (Figure 6A) models. These data revealed that the GG genotype of MDM2 rs2279744 was statistically associated with increased SCC susceptibility.

Furthermore, subgroup analyses by ethnicity (Asian/ Caucasian), HWE $(P>0.05 / P<0.05)$, source of control (population-based/hospital-based), and SCC type (HNSCC/
SSCC/ESCC/OSCC/CSCC/LSCC) were performed for all genetic models. As shown in Table 3, a significantly increased SCC risk was observed in the Asian population in four models ( $\mathrm{G}$ vs T, OR 1.12, $P=0.027$; GG vs TT, OR 1.26, $P=0.016$; GG vs TT + TG, OR $1.25, P<0.001$; carrier G vs $\mathrm{T}$, OR 1.08, $P=0.023)$. Similar results were obtained in the HWE $P>0.05$ group and the population-based group for the allele, homozygote, recessive, and carrier models (Table 3 , all $\mathrm{OR}>1, P<0.05)$. These data further indicated an association between the GG genotype of MDM2 rs2279744 and increased SCC susceptibility in the Asian population. The results of stratified analyses by SCC type showed that a significantly increased ESCC risk was observed for three models (Table 4; G vs T, OR 1.19, $P<0.001$; GG vs TT, OR 1.46, $P<0.001 ; \mathrm{GG}$ vs TT + TG, OR 1.48, $P=0.005$ ). In addition, an increased SSCC risk was observed in the G vs T model (Table 4, OR 1.16, $P=0.022$ ) and the TG + GG vs TT model (OR 1.22, $P=0.028$ ), while an increased LSCC risk was only observed in the TG + GG vs TT model (Table 4, OR 1.18, $P=0.045)$. In contrast, no significant difference was observed for OSCC and CSCC group in any genetic models (Table 4, test of association, all $P>0.05$ ). These data further suggested that patients with the GG genotype of MDM2 rs2279744 appeared to be at a higher risk of developing ESCC in the Asian population. 


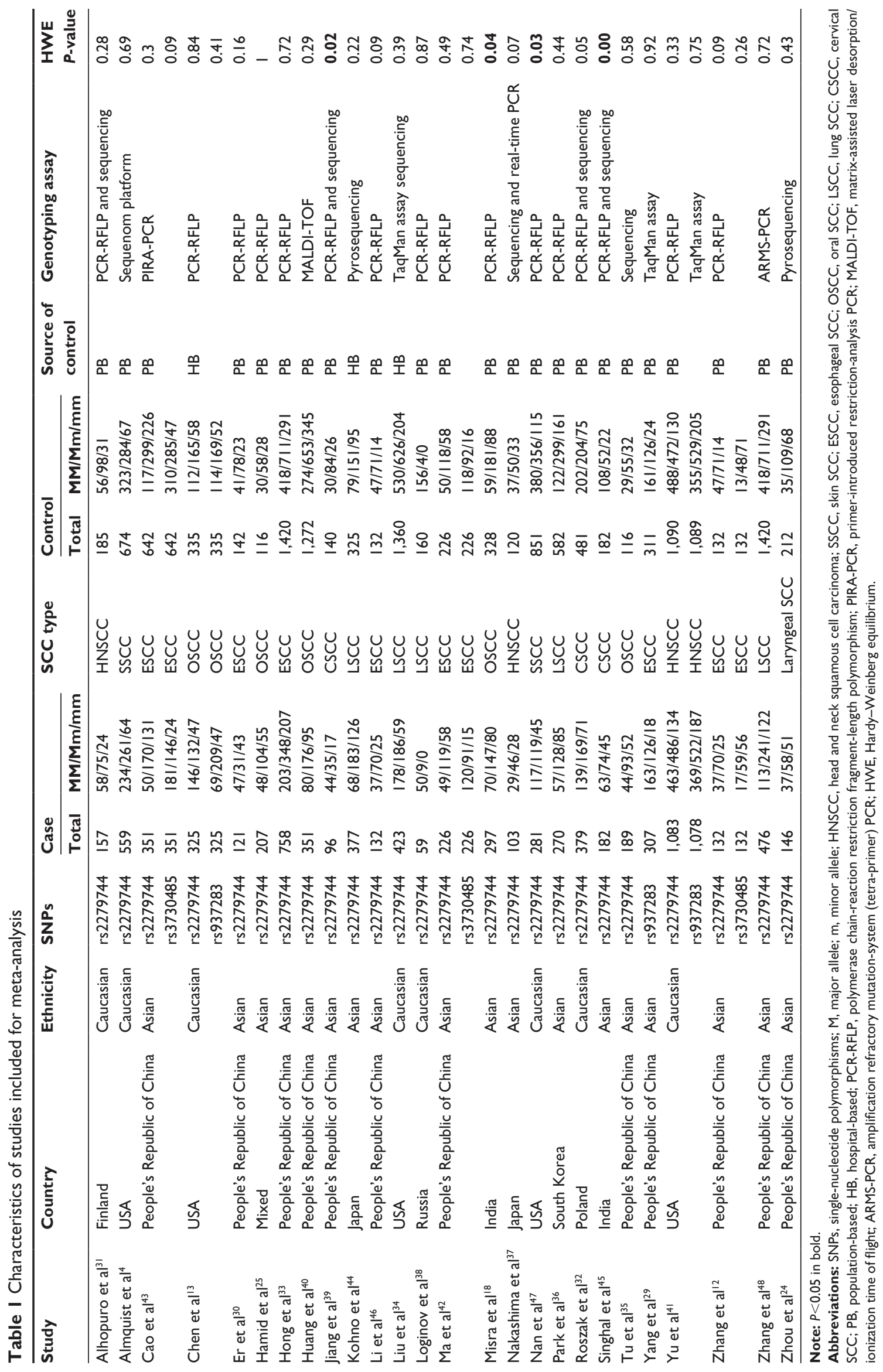


Table 2 Meta analysis of the association between MDM2 polymorphisms (rs2279744, rs937283, and rs3730485) and SCC susceptibility

\begin{tabular}{|c|c|c|c|c|c|c|c|c|c|c|c|c|c|}
\hline \multirow[t]{2}{*}{$\overline{\text { SNP }}$} & \multirow[t]{2}{*}{ Comparison } & \multirow{2}{*}{$\begin{array}{l}\text { No of case- } \\
\text { control } \\
\text { studies }\end{array}$} & \multirow{2}{*}{$\begin{array}{l}\text { Case/control } \\
\text { total sample } \\
\text { size }\end{array}$} & \multicolumn{3}{|c|}{ Test of association } & \multicolumn{2}{|c|}{ Heterogeneity } & \multirow[t]{2}{*}{ Model } & \multicolumn{2}{|c|}{ Begg $^{a}$} & \multicolumn{2}{|l|}{ Egger } \\
\hline & & & & OR & $95 \% \mathrm{Cl}$ & $P$-value & $I^{2}(\%)$ & $P$-value & & $\mathbf{z}$ & $P$-value & $t$ & $P$-value \\
\hline rs2279744 & G vs $T$ & 25 & $7,680 / 12,643$ & 1.09 & $1-1.19$ & 0.041 & 70 & $<0.001$ & $R$ & 0.05 & 0.963 & 0.43 & 0.671 \\
\hline rs2279744 & GG vs TT & 24 & $7,621 / 12,483$ & 1.17 & $1.02-1.36$ & 0.030 & 59.1 & $<0.001$ & $R$ & 0.05 & 0.96 & -0.33 & 0.744 \\
\hline rs2279744 & TG vs TT & 25 & $7,680 / 12,643$ & I & $0.87-1.15$ & 0.975 & 72.9 & $<0.001$ & $R$ & 0.79 & 0.427 & -0.48 & 0.637 \\
\hline rs2279744 & TG + GG vs TT & 25 & $7,680 / 12,643$ & 1.06 & $0.92-1.21$ & 0.422 & 73.7 & $<0.001$ & $\mathrm{R}$ & 0.47 & 0.64 & -0.18 & 0.861 \\
\hline rs2279744 & GG vs TT + TG & 24 & $7,621 / 12,483$ & 1.18 & $1.07-1.3$ & 0.001 & 36.3 & 0.04 & $\mathrm{R}$ & 0.74 & 0.457 & 0.52 & 0.607 \\
\hline rs2279744 & carrier G vs $\mathrm{T}$ & 25 & $7,680 / 12,643$ & 1.06 & $1-1.13$ & 0.064 & 31.5 & 0.068 & $R$ & 0.09 & 0.926 & 0.78 & 0.446 \\
\hline rs937283 & G vs $A$ & 3 & I,7I0/I,735 & 1.02 & $0.84-1.24$ & 0.803 & 67 & 0.048 & $\mathrm{R}$ & 0 & I & 0.57 & 0.668 \\
\hline rs937283 & GG vs $A A$ & 3 & I,710/I,735 & 0.99 & $0.69-1.43$ & 0.957 & 52 & 0.124 & $R$ & 0 & I & 0.33 & 0.795 \\
\hline rs937283 & $A G$ vs $A A$ & 3 & $1,710 / 1,735$ & 1.22 & $0.78-1.9$ & 0.377 & 85.7 & 0.001 & $\mathrm{R}$ & 1.04 & 0.296 & 1.05 & 0.485 \\
\hline rs937283 & $A G+G G$ vs $A A$ & 3 & $1,710 / 1,735$ & 1.17 & $0.77-1.77$ & $0.46 \mathrm{I}$ & 85.3 & 0.001 & $R$ & 1.04 & 0.296 & 1.01 & 0.498 \\
\hline rs937283 & $G G$ vs $A A+A G$ & 3 & I,710/I,735 & 0.89 & $0.74-1.08$ & 0.231 & 0 & 0.84 & $\mathrm{~F}$ & 1.04 & 0.296 & -1.02 & 0.493 \\
\hline rs937283 & carrier $\mathrm{G}$ vs $\mathrm{A}$ & 3 & I,710/I,735 & I & $0.89-1.12$ & 0.992 & 9.8 & 0.33 & $\mathrm{~F}$ & 0 & I & 0.59 & 0.659 \\
\hline rs3730485 & $-v s+$ & 3 & $709 / 1,000$ & 0.89 & $0.76-1.04$ & 0.130 & 0 & 0.428 & $\mathrm{~F}$ & 0 & I & -0.81 & 0.567 \\
\hline rs3730485 & $-I-v s+/+$ & 3 & $709 / 1,000$ & 0.82 & $0.56-1.19$ & 0.294 & 0 & 0.7 & $F$ & 1.04 & 0.296 & -0.69 & 0.614 \\
\hline rs3730485 & $+/-$ vs $+/+$ & 3 & $709 / 1,000$ & 0.91 & $0.73-1.13$ & 0.387 & 0 & 0.909 & $\mathrm{~F}$ & 0 & I & 0.64 & 0.637 \\
\hline rs3730485 & $+/-,-I-$ vs $+/+$ & 3 & $709 / 1,000$ & 0.89 & $0.73-1.1$ & 0.275 & 0 & 0.809 & $\mathrm{~F}$ & 0 & I & -0.53 & 0.688 \\
\hline rs3730485 & $-I-$ vs $+/+,+/-$ & 3 & $709 / 1,000$ & 0.79 & $0.58-1.09$ & 0.146 & 0 & 0.5 & $\mathrm{~F}$ & 0 & I & 0.62 & 0.648 \\
\hline rs3730485 & Carrier - vs + & 3 & $709 / 1,000$ & 0.92 & $0.77-1.09$ & 0.315 & 0 & 0.684 & $\mathrm{~F}$ & 0 & I & -0.81 & 0.566 \\
\hline
\end{tabular}

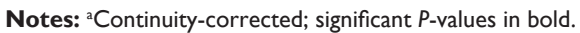

Abbreviations: SCC, squamous cell carcinoma; OR, odds ratio; Cl, confidence interval; F, fixed-effect model; R, random-effect model.

\section{Polymorphisms rs937283 and rs3730485 of MDM2 and SCC susceptibility}

Next, pooled analysis for the association between the rs 937283 and rs3730485 polymorphisms of MDM2 and the risks of SCC was conducted (Table 2). A random-effect model was used for the comparison of $\mathrm{G}$ vs $\mathrm{A}, \mathrm{GG}$ vs $\mathrm{AA}, \mathrm{AG}$ vs $\mathrm{AA}$, $\mathrm{AG}+\mathrm{GG}$ vs AA, due to the presence of heterogeneity (all heterogeneity tests, $I^{2}>50 \%$ ), whereas a fixed-effect model was used for others. No significant difference was observed for any genetic models (Table 2, test of association, all $P>0.05)$. The data failed to provide strong evidence regarding the association between the rs937283 and rs3730485 polymorphisms of MDM2 and overall SCC susceptibility.

\section{MDM2/TP53 mutations and SCC susceptibility}

The MDM2 rs2279744 polymorphism has been reported to suppress the $\mathrm{p} 53$ pathway via the modulation of MDM2 expression. ${ }^{2,49} \mathrm{We}$ also investigated the genetic relationship between SCC risks and MDM2/TP53 mutations, including $M D M 2^{+} / T P 53^{-}, M D M 2^{-} / T P 53^{+}$, and $M D M 2^{+} / T P 53^{+}$. Specific genotype information is shown in Table 5. A random-effect model was used. The data in Table 5 show significant differences for the $M D M 2^{+} / T P 53^{+}$double mutation in the overall population (test of association, OR 1.52,
95\% CI 1.19-1.95; $P=0.001)$ and the Asian population (test of association, OR 1.49, 95\% CI 1.06-2.11; $P=0.022$ ). However, no significant difference was observed for other mutations (test of association, all $P>0.05$ ). According to our data, the combined effect of the MDM2/TP53 double mutation may contribute to an increased SCC risk, especially in the Asian population.

\section{Publication bias and sensitivity analysis}

The results of Begg's funnel plots and Egger's publicationbias plots demonstrated that the occurrence of large publication bias was excluded under all genetic models (Tables 2 and 4, all $P>0.05$ ), apart from the mutations of $M D M 2^{+} / T^{-} 53^{-}$and $M D M 2^{+} / T P 53^{+}$in the Caucasian group (Table 4, Egger's publication-bias plot, $P<0.05$ ). Egger's funnel plots of publication bias for the allele (Figure 2B), homozygote (Figure 3B), heterozygote (Figure 4B), dominant (Figure 5B), and recessive (Figure 6B) models of $M D M 2$ rs2279744 polymorphism are shown. With regard to the sensitivity analysis, compared with overall meta-analysis data, no significant difference for the pooled OR value was observed when each study was omitted sequentially (Figure 2C for allele model of MDM2 rs2279744; Figure 3C for homozygote model; Figure 4C for heterozygote model; Figure $5 \mathrm{C}$ for dominant model; Figure $6 \mathrm{C}$ for recessive 
A

Allele model (G vs T)

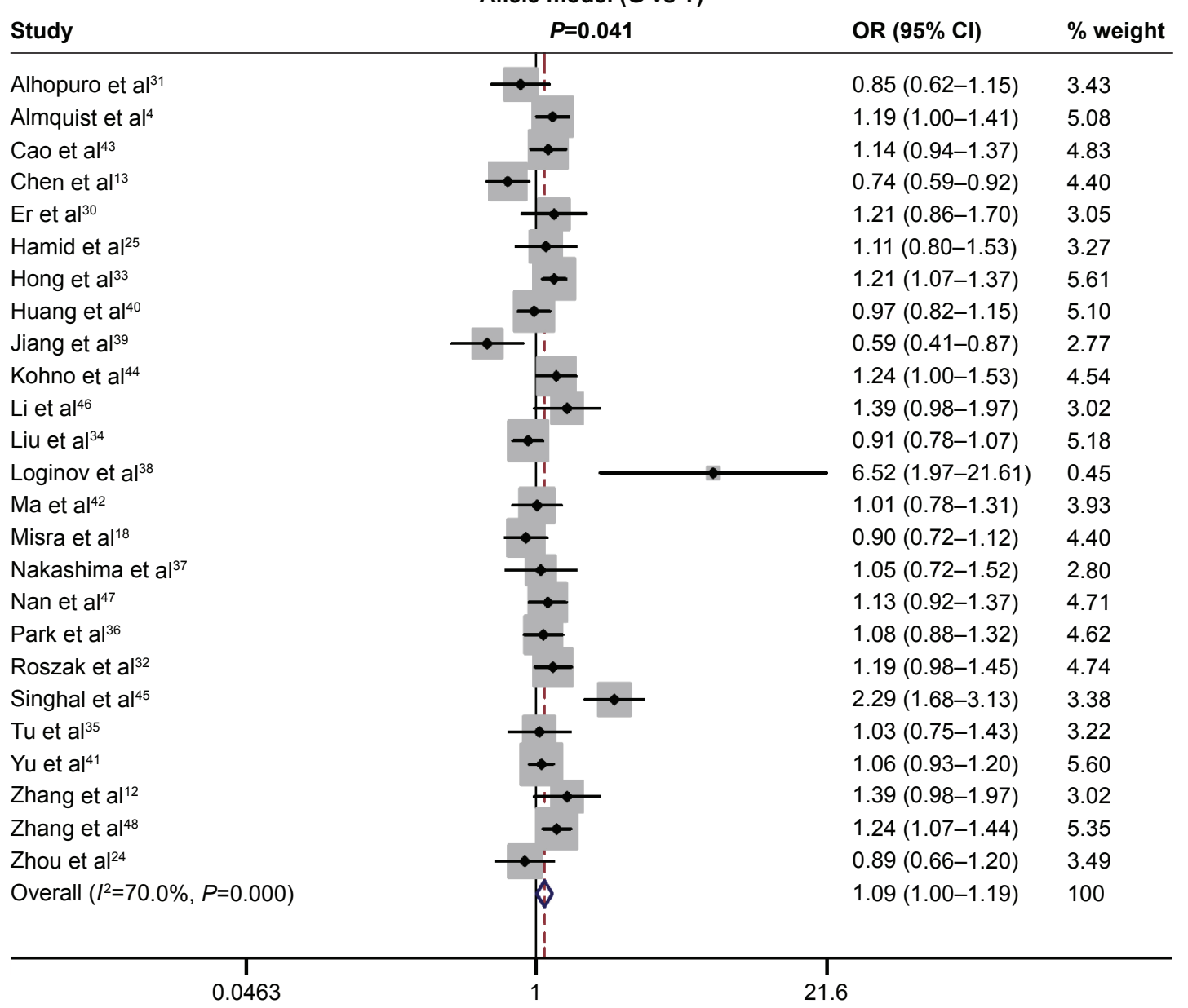

B

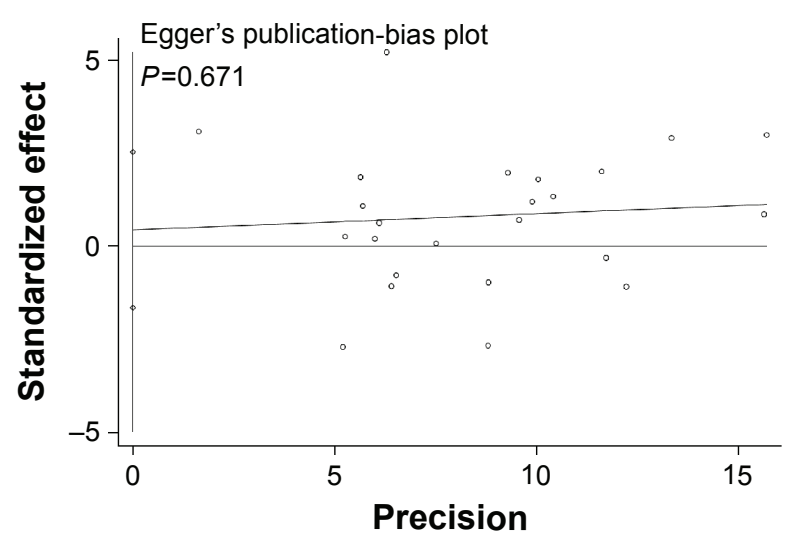

C

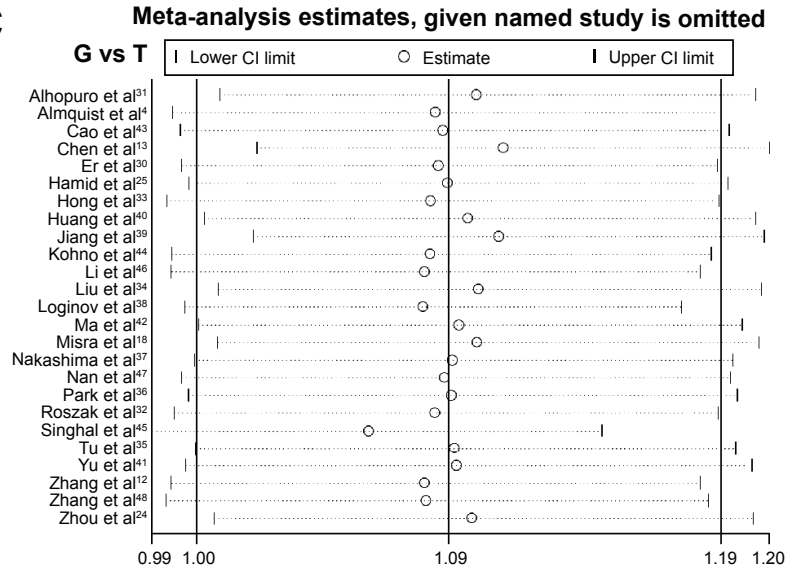

Figure 2 Meta-analysis of the association between MDM2 rs2279744 and SCC susceptibility under the G vs T model.

Notes: (A) Forest plot; (B) Egger's funnel plot of publication-bias; (C) sensitivity analysis. Weights are from random-effect analysis.

Abbreviations: SCC, squamous cell carcinoma; OR, odds ratio; $\mathrm{Cl}$, confidence interval.

model; data not shown for others). Consequently, these data suggested that our statistical results were credible.

\section{Discussion}

More and more studies on the possible role of the $M D M 2$ rs2279744 polymorphism in the onset and development of cancer have been reported. Hu et al performed a meta-analysis based on 25 published case-control studies, and reported that MDM2 rs2279744 seems to be associated with tumor susceptibility. ${ }^{50}$ Chen et al reported that the MDM2 rs2279744 polymorphism may be linked to an increased digestive tract cancer risk in the Asian population. ${ }^{51}$ 
A
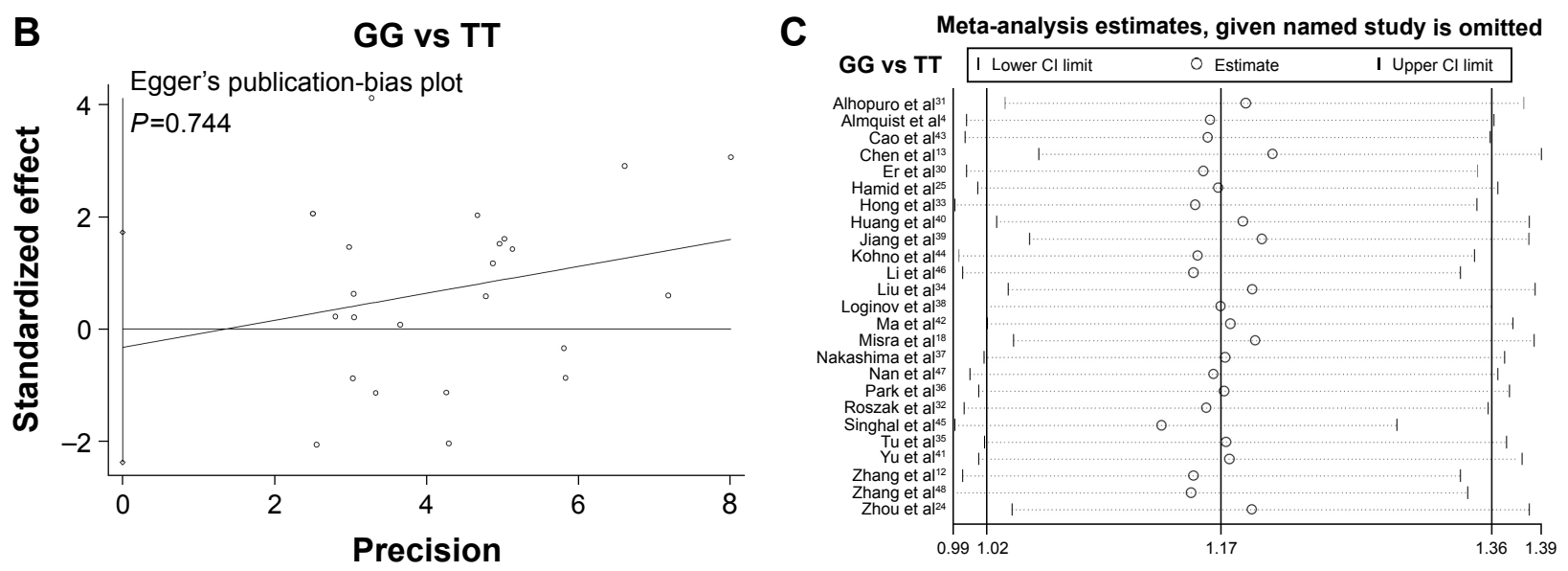

Figure 3 Meta-analysis of the association between MDM2 rs2279744 and SCC susceptibility under the GG vs TT model.

Notes: (A) Forest plot; (B) Egger's funnel plot of publication-bias; (C) sensitivity analysis. Weights are from random-effect analysis.

Abbreviations: SCC, squamous cell carcinoma; OR, odds ratio; $\mathrm{Cl}$, confidence interval.

Here, we further focused on the potential effect of $M D M 2$ rs2279744 in susceptibility to overall SCC and specific SCC types, including HNSCC, SSCC, ESCC, OSCC, CSCC, and LSCC.

Several SCC-related meta-analyses have been carried out previously. A meta-analysis by Liu et al based on seven articles with 1,629 cases and 2,472 controls showed that the G allele of the MDM2 rs2279744 polymorphism seemed to act as an important HNSCC protective factor in the Caucasian population, but not the Asian population. ${ }^{26}$ However, in our meta-analysis, we were unable to observe a significant association between HNSCC susceptibility and MDM2 
A

\begin{tabular}{|c|c|c|c|}
\hline \multicolumn{4}{|c|}{ Heterozygote model (TG vs TT) } \\
\hline Study & $P=0.975$ & OR (95\% Cl) & $\%$ weight \\
\hline Alhopuro et $\mathrm{al}^{31}$ & - & $0.74(0.46-1.19)$ & 3.67 \\
\hline Almquist et $\mathrm{al}^{4}$ & 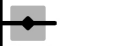 & $1.27(1.00-1.61)$ & 5.29 \\
\hline Cao et $\mathrm{al}^{43}$ & & $1.33(0.91-1.95)$ & 4.30 \\
\hline Chen et $\mathrm{al}^{13}$ & & $0.61(0.44-0.86)$ & 4.61 \\
\hline Er et $\left.a\right|^{30}$ & & $0.35(0.19-0.63)$ & 3.00 \\
\hline Hamid et $\mathrm{al}^{25}$ & & $1.12(0.64-1.96)$ & 3.18 \\
\hline Hong et $\mathrm{al}^{33}$ & & $1.01(0.82-1.24)$ & 5.46 \\
\hline Huang et $\mathrm{al}^{40}$ & & $0.92(0.68-1.25)$ & 4.87 \\
\hline Jiang et $\mathrm{al}^{39}$ & & $0.28(0.15-0.52)$ & 2.91 \\
\hline Kohno et $\mathrm{al}^{44}$ & & $1.41(0.95-2.08)$ & 4.24 \\
\hline Li et $\mathrm{al}^{46}$ & & $1.25(0.73-2.15)$ & 3.26 \\
\hline Liu et $\mathrm{al}^{34}$ & & $0.88(0.70-1.12)$ & 5.31 \\
\hline Loginov et $\mathrm{al}^{38}$ & & $7.02(2.07-23.78)$ & 1.12 \\
\hline Ma et $\mathrm{al}^{42}$ & & $1.03(0.64-1.65)$ & 3.71 \\
\hline Misra et $\mathrm{al}^{18}$ & & $0.68(0.45-1.03)$ & 4.10 \\
\hline Nakashima et $\mathrm{al}^{37}$ & & $1.17(0.63-2.20)$ & 2.80 \\
\hline Nan et $\mathrm{al}^{47}$ & & $1.09(0.81-1.46)$ & 4.91 \\
\hline Park et al ${ }^{36}$ & & $0.92(0.63-1.34)$ & 4.33 \\
\hline Roszak et al ${ }^{32}$ & & $1.20(0.89-1.62)$ & 4.89 \\
\hline Singhal et al ${ }^{45}$ & 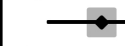 & $2.44(1.52-3.91)$ & 3.69 \\
\hline Tu et $\mathrm{al}^{35}$ & - & $1.11(0.63-1.98)$ & 3.08 \\
\hline Yu et $\mathrm{al}^{41}$ & $\rightarrow$ & $1.09(0.91-1.30)$ & 5.65 \\
\hline Zhang et al ${ }^{12}$ & 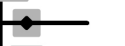 & $1.25(0.73-2.15)$ & 3.26 \\
\hline Zhang et al ${ }^{48}$ & 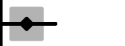 & $1.25(0.97-1.62)$ & 5.19 \\
\hline Zhou et al24 & & $0.50(0.29-0.88)$ & 3.16 \\
\hline Overall $\left(I^{2}=72.9 \%, P=0.000\right)$ & $b$ & $1.00(0.87-1.15)$ & 100 \\
\hline
\end{tabular}

B TG vs TT

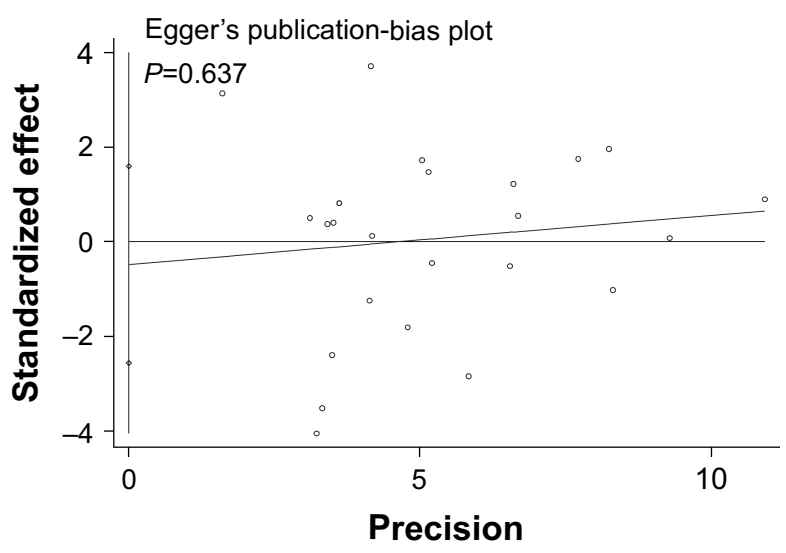

C

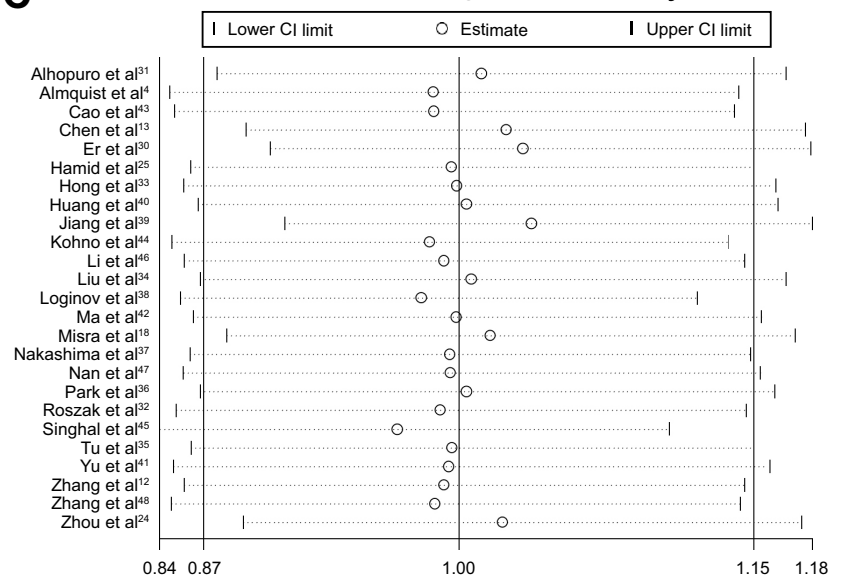

Figure 4 Meta-analysis of the association between MDM2 rs2279744 and SCC susceptibility under the TG vs TT model.

Notes: (A) Forest plot; (B) Egger's funnel plot of publication-bias; (C) sensitivity analysis. Weights are from random-effect analysis.

Abbreviations: SCC, squamous cell carcinoma; OR, odds ratio; $\mathrm{Cl}$, confidence interval.

rs2279744. How to explain this? Seven studies were enrolled in the meta-analysis of Liu et al. ${ }^{13,18,25,31,33,35,37}$ Also, data for OSCC in five studies ${ }^{13,18,25,33,35}$ were included as HNSCC. The disease in two studies ${ }^{31,37}$ was defined only as HNSCC. In our subgroup analysis, we tested the relationship between OSCC risk and $M D M 2$ rs2279744. One new study ${ }^{41}$ was added in the new meta-analysis for HNSCC. We found that the MDM2 rs2279744 polymorphism did not appear to be associated with OSCC susceptibility, which is partly consistent with the results of Xie et al. ${ }^{27}$ 
Dominant model (TG + GG vs TT)

Study

Alhopuro et $\mathrm{al}^{3}$

Almquist et al ${ }^{4}$

Cao et $\mathrm{al}^{43}$

Chen et al ${ }^{13}$

Er et $\mathrm{a}^{30}$

Hamid et $\mathrm{al}^{25}$

Hong et $\mathrm{al}^{33}$

Huang et al ${ }^{40}$

Jiang et al ${ }^{39}$

Kohno et $\mathrm{al}^{44}$

Li et al ${ }^{46}$

Liu et $a^{34}$

Loginov et $a^{38}$

Ma et $\mathrm{al}^{42}$

Misra et al ${ }^{18}$

Nakashima et $\mathrm{al}^{37}$

Nan et al ${ }^{47}$

Park et $\mathrm{al}^{36}$

Roszak et al ${ }^{32}$

Singhal et $\mathrm{a}^{45}$

Tu et $\mathbf{a l}^{35}$

Yu et $\mathrm{al}^{41}$

Zhang et al $^{12}$

Zhang et $\mathrm{al}^{48}$

Zhou et $\mathrm{al}^{24}$

Overall $\left(I^{2}=73.7 \%, P=0.000\right)$

\section{$P=0.422$}

OR $(95 \% \mathrm{Cl})$

$\%$ weight

$0.74(0.47-1.16) \quad 3.65$

$1.28(1.02-1.60) \quad 5.23$

$1.34(0.94-1.92) \quad 4.28$

$0.62(0.45-0.84) \quad 4.60$

$0.64(0.38-1.07) \quad 3.25$

$1.16(0.68-1.96) \quad 3.19$

$1.14(0.941 .39) \quad 5.42$

$0.93(0.70-1.23) \quad 4.83$

$0.32(0.18-0.57) \quad 2.94$

$1.46(1.01-2.10) \quad 4.24$

$1.42(0.84-2.39) \quad 3.22$

$0.88(0.70-1.10) \quad 5.26$

$7.02(2.07-23.78) \quad 1.03$

$1.03(0.66-1.60) \quad 3.68$

$0.71(0.48-1.05) \quad 4.07$

$1.14(0.64-2.03) \quad 2.90$

$1.13(0.86-1.49) \quad 4.91$

$0.99(0.70-1.41) \quad 4.32$

$1.25(0.95-1.65) \quad 4.88$

$2.76(1.80-4.22) \quad 3.82$

$1.10(0.64-1.88) \quad 3.11$

$1.09(0.92-1.29) \quad 5.59$

$1.42(0.84-2.39) \quad 3.22$

$1.34(1.05-1.70) \quad 5.14$

$0.58(0.35-0.98) \quad 3.22$

$1.06(0.92-1.21) \quad 100$
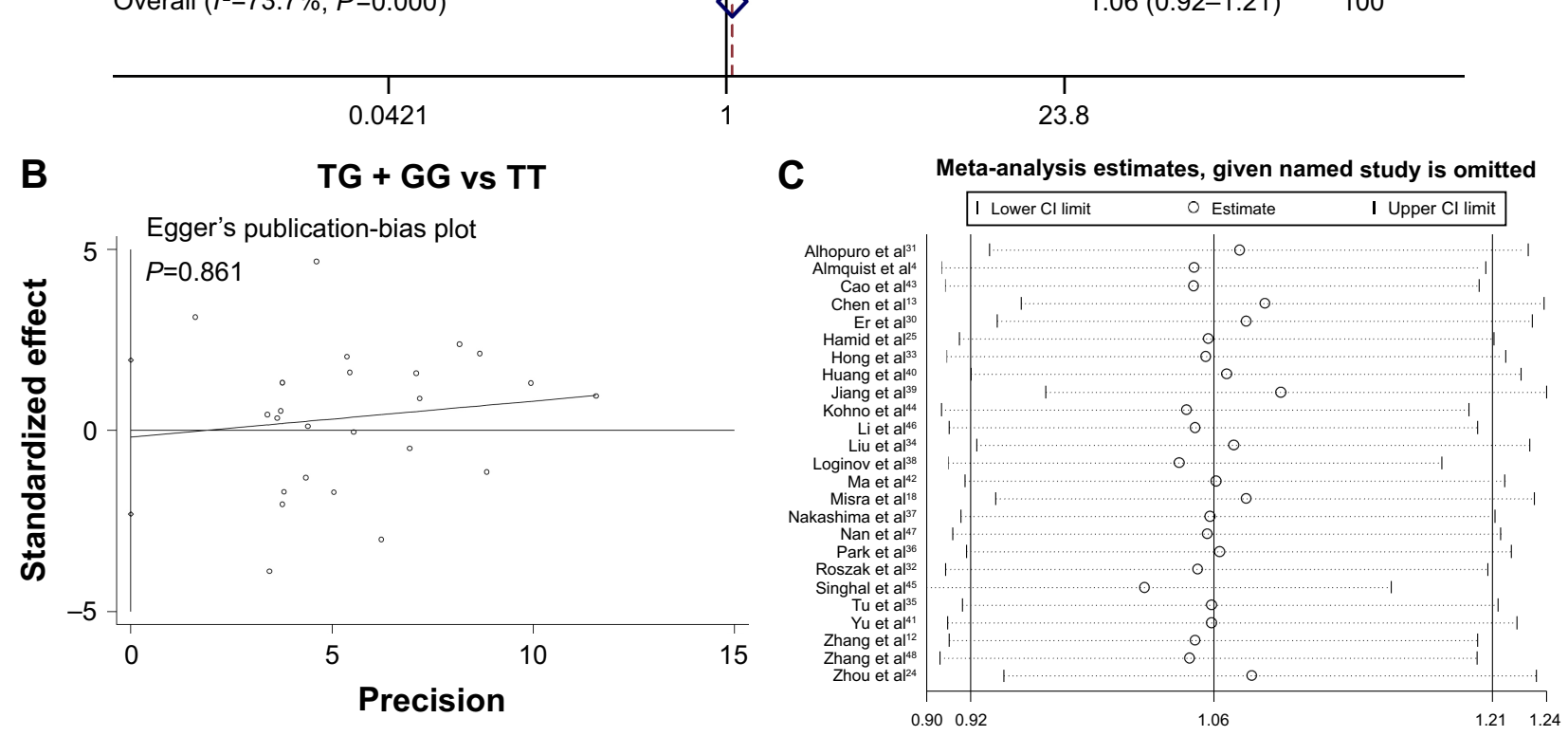

Figure 5 Meta-analysis of the association between MDM2 rs2279744 and SCC susceptibility under the TG + GG vs TT model.

Notes: (A) Forest plot; (B) Egger's funnel plot of publication-bias; (C) sensitivity analysis. Weights are from random-effect analysis.

Abbreviations: SCC, squamous cell carcinoma; OR, odds ratio; $\mathrm{Cl}$, confidence interval.

A meta-analysis by Chen et al based on six case-control studies, including 1,899 cases and 3,016 controls, showed that the MDM2 rs2279744 polymorphism may be associated with increased risks of overall esophageal cancer, including SCC and adenocarcinoma, especially in the Asian population. ${ }^{28}$
However, our meta-analysis only targeted the ESCCs. We thus removed one study on esophageal adenocarcinoma ${ }^{52}$ and added another new published case-control study. ${ }^{12}$ All cases in six case-control studies were Chinese patients, with a mean age of $>50$ years and male:female ratio of $>50 \%$. The 
A

Recessive model (GG vs TT + TG)

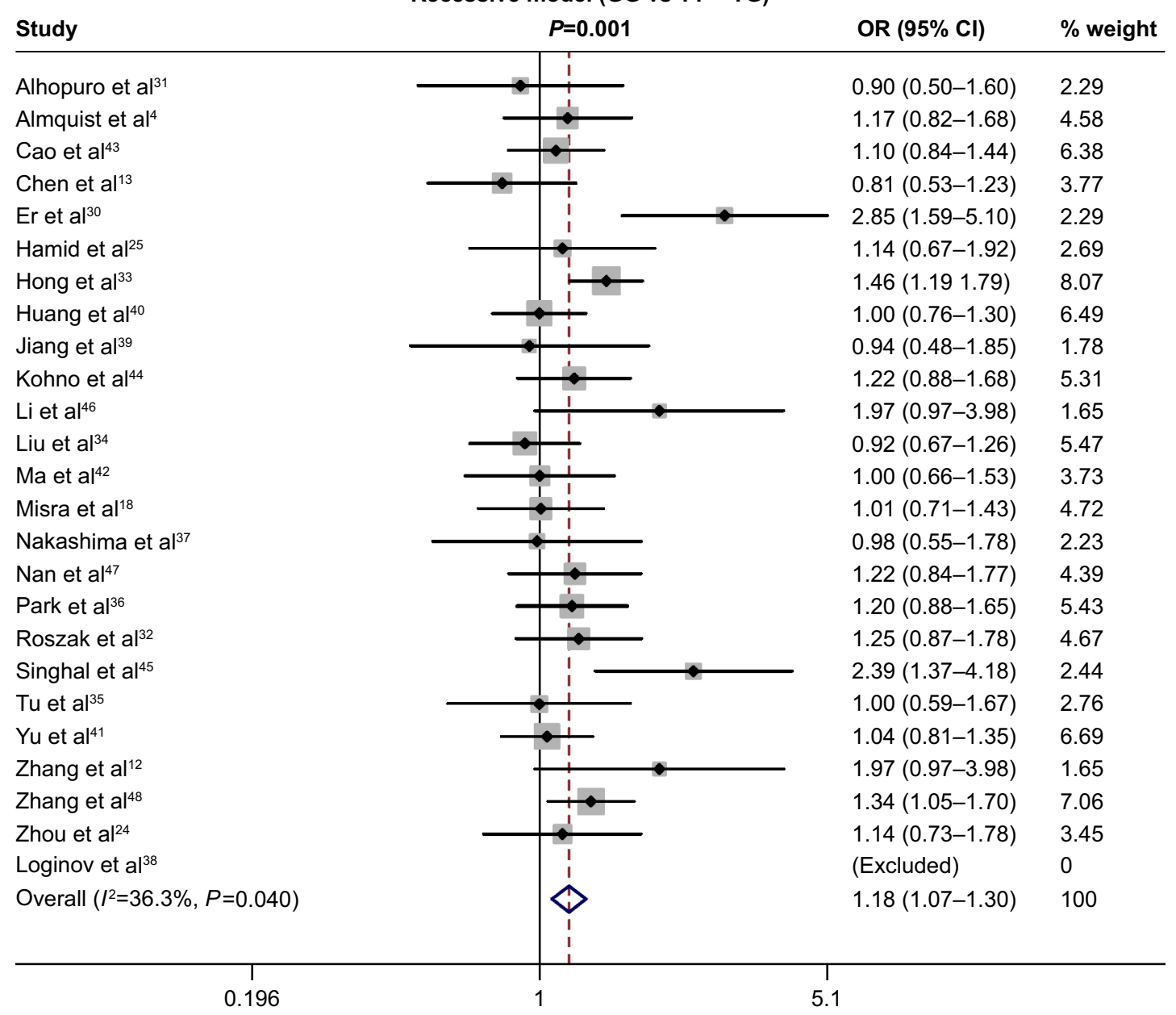
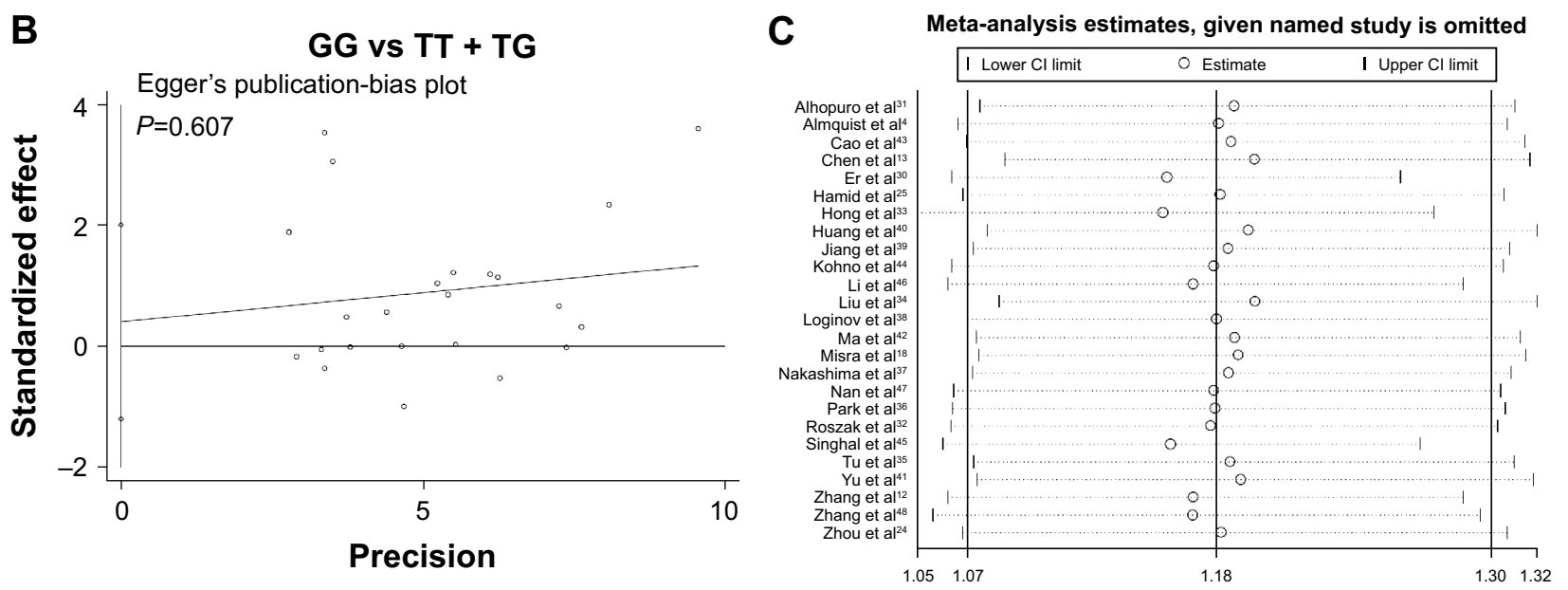

Figure 6 Meta-analysis of the association between MDM2 rs2279744 and SCC susceptibility under the GG vs TT + TG model.

Notes: (A) Forest plot; (B) Egger's funnel plot of publication-bias; (C) sensitivity analysis. Weights are from random-effect analysis.

Abbreviations: SCC, squamous cell carcinoma; $\mathrm{OR}$, odds ratio; $\mathrm{Cl}$, confidence interval.

GG genotype of MDM2 rs2279744 was likely to confer an increased susceptibility to ESCC in elderly male patients in People's Republic of China. The influence of habits and customs, such as drinking or smoking, should be considered.
Considering the close association between $M D M 2$ and $\mathrm{p} 53,{ }^{2-5}$ it is meaningful to investigate the role of gene-gene interaction between MDM2 and TP53 Arg72Pro polymorphism in SCC risks. In our meta-analysis, we observed a 
Table 3 Subgroup analysis by ethnicity, source of controls, and HWE for association between MDM2 rs2279744 and SCC susceptibility

\begin{tabular}{|c|c|c|c|c|c|c|}
\hline \multirow[t]{2}{*}{ Comparison } & \multicolumn{2}{|l|}{ Ethnicity } & \multicolumn{2}{|l|}{ HWE } & \multicolumn{2}{|c|}{ Source of control } \\
\hline & Asian & Caucasian & $\mathbf{Y}$ & $\mathbf{N}$ & PB & HB \\
\hline \multicolumn{7}{|l|}{ G vs $T$} \\
\hline No of case-control studies & 17 & 8 & 21 & 4 & 22 & 3 \\
\hline Case/control total sample size & $4,4 \mid 4 / 7,507$ & $3,266 / 5,136$ & $6,824 / 11,142$ & $856 / 1,501$ & $6,555 / 10,623$ & $\mathrm{I}, 125 / 2,020$ \\
\hline OR $(95 \% \mathrm{Cl})$ & $1.12(1.01-1.24)$ & $1.03(0.89-1.19)$ & $1.09(1.01-1.17)$ & $\mathrm{I} .09(0.69-1.7 \mathrm{I})$ & $1.12(1.03-1.22)$ & $0.94(0.72-1.23)$ \\
\hline$P$-value & 0.027 & 0.669 & 0.026 & 0.711 & 0.011 & 0.662 \\
\hline \multicolumn{7}{|l|}{ GG vs TT } \\
\hline No of case-control studies & 17 & 7 & 20 & 4 & 21 & 3 \\
\hline Case/control total sample size & $4,4 \mid 4 / 7,507$ & $3,207 / 4,976$ & $6,765 / 10,982$ & $856 / 1,501$ & $6,496 / 10,463$ & $1,125 / 2,020$ \\
\hline OR $(95 \% \mathrm{Cl})$ & $1.26(1.04-1.52)$ & $1.03(0.84-1.27)$ & $1.18(1.03-1.34)$ & $1.13(0.55-2.34)$ & $1.22(|.05-| .4 \mid)$ & $0.94(0.58-1.53)$ \\
\hline$P$-value & 0.016 & 0.755 & 0.015 & 0.74 & 0.008 & 0.805 \\
\hline \multicolumn{7}{|l|}{ TG vs TT } \\
\hline No of case-control studies & 17 & 8 & 21 & 4 & 22 & 3 \\
\hline Case/control total sample size & $4,4 \mid 4 / 7,507$ & $3,266 / 5,136$ & $6,824 / I I, I 42$ & $856 / I, 501$ & $6,555 / 10,623$ & $\mathrm{I}, 125 / 2,020$ \\
\hline OR $(95 \% \mathrm{Cl})$ & $0.97(0.8-1.1)$ & $0.97(0.8-1.19)$ & $1.02(0.89-1.16)$ & $0.87(0.42-1.77)$ & I.0I (0.87-I.I8) & $0.9(0.6-1.36)$ \\
\hline$P$-value & 0.781 & 0.805 & 0.818 & 0.691 & 0.857 & 0.629 \\
\hline \multicolumn{7}{|l|}{ TG + GG vs TT } \\
\hline No of case-control studies & 17 & 8 & 21 & 4 & 22 & 3 \\
\hline Case/control total sample size & $4,4 \mid 4 / 7,507$ & $3,266 / 5,136$ & $6,824 / I I, I 42$ & $856 / 1,501$ & $6,555 / 10,623$ & $\mathrm{I}, 125 / 2,020$ \\
\hline OR $(95 \% \mathrm{Cl})$ & $1.06(0.88-1.28)$ & $1.04(0.84-1.28)$ & $1.07(0.95-1.2)$ & $0.94(0.45-1.94)$ & $1.08(0.94-1.25)$ & $0.91(0.6-1.4)$ \\
\hline$P$-value & 0.527 & 0.736 & 0.279 & 0.86 & 0.269 & 0.682 \\
\hline \multicolumn{7}{|l|}{ GG vs TT + TG } \\
\hline No of case-control studies & 17 & 7 & 20 & 4 & 21 & 3 \\
\hline Case/control total sample size & $4,4 \mid 4 / 7,507$ & $3,207 / 4,976$ & $6,765 / 10,982$ & $856 / 1,501$ & $6,496 / 10,463$ & $\mathrm{I}, 125 / 2,020$ \\
\hline OR $(95 \% \mathrm{Cl})$ & $1.25(1.11-1.42)$ & $1.05(0.92-1.2)$ & $1.17(1.06-1.29)$ & $1.27(0.88-1.83)$ & $1.22(1.1-1.35)$ & $0.99(0.78-1.24)$ \\
\hline$P$-value & $<0.001$ & $0.50 \mathrm{I}$ & 0.002 & 0.197 & $<0.001$ & 0.911 \\
\hline \multicolumn{7}{|l|}{ Carrier G vs T } \\
\hline No of case-control studies & 17 & 8 & 21 & 4 & 22 & 3 \\
\hline Case/control total sample size & $4,4 \mid 4 / 7,507$ & $3,266 / 5,136$ & $6,824 / 11,142$ & $856 / I, 501$ & $6,555 / 10,623$ & $\mathrm{I}, 125 / 2,020$ \\
\hline OR $(95 \% \mathrm{Cl})$ & $1.08(1.01-1.16)$ & $1.03(0.91-1.16)$ & $1.06(1.01-1.12)$ & $\mathrm{I} .07(0.77-\mathrm{I} .5)$ & $1.08(1.01-1.15)$ & $1.06(I-I .13)$ \\
\hline$P$-value & 0.023 & 0.672 & 0.031 & 0.676 & 0.018 & 0.618 \\
\hline
\end{tabular}

Note: Significant $P$-values in bold.

Abbreviations: HWE, Hardy-Weinberg equilibrium; SCC, squamous cell carcinoma; PB, population-based; HB, hospital-based; Y, $P$-value of HWE $>0.05$; N, $P$-value of $\mathrm{HWE}<0.05$; OR, odds ratio; $\mathrm{Cl}$, confidence interval.

positive association between $M D M 2^{+} / T P 53^{+}$double mutation and SCC susceptibility in overall or Asian populations. The underlying molecular mechanism on the effect of MDM2 genetic variation in the incidence of ESCC remains unclear. The rs2279744 SNP within the promoter region of MDM2 can lead to a $\mathrm{T}-\mathrm{G}$ substitution at the 309 nucleotide site, which is closely linked to the high expression of the MDM2 protein via higher binding affinity with the transcriptional activator SP1, and thus enhances the degradation of $\mathrm{p} 53 .{ }^{2}$ It was possible that $M D M 2$ rs 2279744 polymorphism is linked to the increased SCC risks, through influencing the role of p53 pathway in genomic stability and tumor prevention. Chen et al conducted a meta-analysis to investigate the relationship between positive MDM2 expression and clinicopathological characteristics of ESCC, and found that high MDM2 expression was associated with early primary tumor stage and increased risk of regional lymph node metastasis, but not the risk of distant metastasis. ${ }^{53}$ Vlatković et al reported that loss of MTBP expression seems to be associated with reduced survival in some patients with HNSCC. ${ }^{54}$ In addition, several reported studies have estimated the role of the interaction between the MDM2/TP53 gene and several environmental factors, including smoking exposure, alcohol consumption, or human papillomavirus infections in SCC susceptibility. ${ }^{13,29,38,40,41}$ For instance, rs2279744 and rs937283 of MDM2 might be associated 
Table 4 Subgroup analysis by disease type for association between MDM2 rs2279744 and SCC susceptibility

\begin{tabular}{|c|c|c|c|c|c|c|}
\hline Comparison & HNSCC & SSCC & ESCC & oscc & $\operatorname{cscc}$ & LSCC \\
\hline \multicolumn{7}{|l|}{ G vs $T$} \\
\hline No of case-control studies & 3 & 2 & 6 & 5 & 3 & 5 \\
\hline Case/control total sample size & $\mathrm{I}, 186 / 1,210$ & $840 / 1,525$ & $\mathrm{I}, 720 / 2,694$ & $\mathrm{I}, 369 / 2,167$ & $657 / 803$ & $\mathrm{I}, 605 / 3,847$ \\
\hline OR $(95 \% \mathrm{Cl})$ & $1.03(0.92-1.15)$ & $1.16(1.02-1.32)$ & $1.19(1.09-1.3)$ & $0.92(0.8 \mathrm{I}-1.05)$ & $1.19(0.62-2.25)$ & $1.16(0.95-1.42)$ \\
\hline$P$-value & 0.659 & 0.022 & $<\mathbf{0 . 0 0 I}$ & 0.223 & 0.603 & 0.153 \\
\hline \multicolumn{7}{|l|}{ GG vs TT } \\
\hline No of case-control studies & 3 & 2 & 6 & 5 & 3 & 4 \\
\hline Case/control total sample size & $1,186 / 1,210$ & $840 / 1,525$ & $1,720 / 2,694$ & $\mathrm{I}, 369 / 2,167$ & $657 / 803$ & $\mathrm{I}, 546 / 3,687$ \\
\hline OR $(95 \% \mathrm{Cl})$ & $1.03(0.82-|.3|)$ & I.3 (0.98-I.7I) & $1.46(1.23-1.74)$ & $0.86(0.7-1.07)$ & $1.33(0.5-3.52)$ & $1.23(0.92-1.65)$ \\
\hline$P$-value & 0.788 & 0.067 & $<0.001$ & 0.173 & 0.569 & 0.161 \\
\hline \multicolumn{7}{|l|}{ TG vs TT } \\
\hline No of case-control studies & 3 & 2 & 6 & 5 & 3 & 5 \\
\hline Case/control total sample size & $1,186 / 1,210$ & $840 / 1,525$ & $1,720 / 2,694$ & $\mathrm{I}, 369 / 2,167$ & $657 / 803$ & $\mathrm{I}, 605 / 3,847$ \\
\hline OR $(95 \% \mathrm{Cl})$ & $1.02(0.83-1.26)$ & $1.19(0.99-1.43)$ & $0.98(0.72-1.34)$ & $0.82(0.65-1.04)$ & $0.96(0.35-0.62)$ & $1.21(0.88-1.67)$ \\
\hline$P$-value & 0.83 & 0.062 & 0.916 & 0.103 & $0.94 I$ & 0.249 \\
\hline \multicolumn{7}{|l|}{ TG + GG vs TT } \\
\hline No of case-control studies & 3 & 2 & 6 & 5 & 3 & 5 \\
\hline Case/control total sample size & $1,186 / 1,210$ & $840 / 1,525$ & $1,720 / 2,694$ & $I, 369 / 2,167$ & $657 / 803$ & $\mathrm{I}, 605 / 3,847$ \\
\hline OR $(95 \% \mathrm{Cl})$ & $1.02(0.82-1.26)$ & $1.22(1.02-1.45)$ & $1.14(0.94-1.38)$ & $0.84(0.66-1.06)$ & $1.06(0.39-2.85)$ & $1.26(0.91-1.75)$ \\
\hline$P$-value & 0.886 & 0.028 & 0.179 & 0.135 & 0.913 & 0.164 \\
\hline \multicolumn{7}{|l|}{ GG vs TT + TG } \\
\hline No of case-control studies & 3 & 2 & 6 & 5 & 3 & 4 \\
\hline Case/control total sample size & $1,186 / 1,210$ & $840 / 1,525$ & $1,720 / 2,694$ & $\mathrm{I}, 369 / 2,167$ & $657 / 803$ & $\mathrm{I}, 546 / 3,687$ \\
\hline OR $(95 \% \mathrm{Cl})$ & $1.01(0.8 \mathrm{I}-1.26)$ & $1.19(0.92-1.55)$ & $1.48(1.12-1.94)$ & $0.98(0.83-1.16)$ & I.42 (0.88-2.3I) & I.I8 (I-I.38) \\
\hline$P$-value & 0.911 & 0.181 & 0.005 & 0.801 & 0.154 & 0.045 \\
\hline \multicolumn{7}{|l|}{ Carrier G vs T } \\
\hline No of case-control studies & 3 & 2 & 6 & 5 & 3 & 5 \\
\hline Case/control total sample size & $1,186 / 1,210$ & $840 / 1,525$ & $1,720 / 2,694$ & $1,369 / 2,167$ & $657 / 803$ & $\mathrm{I}, 605 / 3,847$ \\
\hline OR $(95 \% \mathrm{Cl})$ & $1.02(0.9-1.16)$ & I.II (0.96-I.29) & $1.12(1.01-1.24)$ & $0.94(0.84-1.06)$ & $1.15(0.7 \mathrm{I}-1.86)$ & I.II (0.92-I.34) \\
\hline$P$-value & 0.766 & 0.148 & 0.028 & 0.326 & 0.581 & 0.268 \\
\hline
\end{tabular}

Note: Significant $P$-values in bold.

Abbreviations: HNSCC, head and neck squamous cell carcinoma; SSCC, skin SCC; ESCC, esophageal SCC; OSCC, oral SCC; CSCC, cervical SCC; LSCC, lung SCC; $\mathrm{OR}$, odds ratio; $\mathrm{Cl}$, confidence interval.

with the occurrence of OSCC patients with HPV16 L1 seropositivity. ${ }^{13}$ However, due to the lack of sufficient data, we failed to carry out a subgroup analysis based on these environmental factors.

Our meta-analysis contained several limitations. Very few publications resulted in small sample sizes for the analysis of MDM2 rs937283 and rs3730485. The possible effect of other unpublished studies on our negative conclusion should be taken into consideration. The same limitation of sample size existed in the meta-analysis of MDM2/ TP53 double mutation and several subgroup analyses of the MDM2 rs2279744 polymorphism. Heterogeneity and potential publication bias may weaken our conclusion. Demographic features, lifestyle, or clinical characteristics were not considered, due to the lack of data. Larger and independent studies are required to validate the association between MDM2/TP53 mutations and susceptibility to different types of SCC.

\section{Conclusion}

Our updated meta-analysis demonstrated that there is a positive association between increased overall SCC risks and the MDM2 rs2279744 polymorphism, rather than rs 937283 or rs3730485. We further provided evidence that the GG genotype of MDM2 rs2279744 is more likely to confer an increased genetic susceptibility to ESCC in the Asian population, particularly in Chinese. MDM2 rs2279744 may be a valuable risk factor or diagnostic biomarker for patients with ESCC in People's Republic of China, and needs more supporting evidence. 


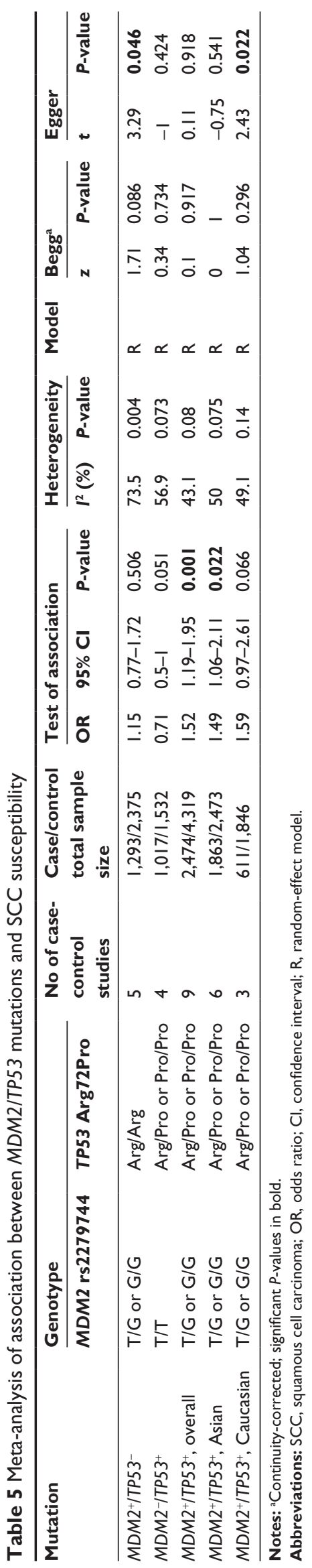

\section{Disclosure}

The authors report no conflicts of interest in this work.

\section{References}

1. Mendoza M, Mandani G, Momand J. The MDM2 gene family. Biomol Concepts. 2014;5(1):9-19.

2. Bond GL, Hu W, Bond EE, et al. A single nucleotide polymorphism in the MDM2 promoter attenuates the p53 tumor suppressor pathway and accelerates tumor formation in humans. Cell. 2004;119(5):591-602.

3. Wei J, Yang Y, Lu M, et al. Escape, or vanish: control the fate of p53 through MDM2-mediated ubiquitination. Anticancer Agents Med Chem. 2015;16(2):174-189.

4. Almquist LM, Karagas MR, Christensen BC, et al. The role of TP53 and MDM2 polymorphisms in TP53 mutagenesis and risk of non-melanoma skin cancer. Carcinogenesis. 2011;32(3):327-330.

5. Zhang Q, Zeng SX, Lu H. Targeting p53-MDM2-MDMX loop for cancer therapy. Subcell Biochem. 2014;85:281-319.

6. Rajendran V. Structural analysis of oncogenic mutation of isocitrate dehydrogenase 1. Mol Biosyst. 2016;12(7):2276-2287.

7. Kumar A, Rajendran V, Sethumadhavan R, Purohit R. In silico prediction of a disease-associated STIL mutant and its affect on the recruitment of centromere protein J (CENPJ). FEBS Open Bio. 2012;2:285-293.

8. Kumar A, Purohit R. Computational screening and molecular dynamics simulation of disease associated nsSNPs in CENP-E. Mutat Res. 2012; 738-739:28-37.

9. Kamaraj B, Rajendran V, Sethumadhavan R, Kumar CV, Purohit R. Mutational analysis of FUS gene and its structural and functional role in amyotrophic lateral sclerosis 6. J Biomol Struct Dyn. 2015;33(4): 834-844.

10. Purohit R. Role of ELA region in auto-activation of mutant KIT receptor: a molecular dynamics simulation insight. J Biomol Struct Dyn. 2014; 32(7):1033-1046.

11. Kumar A, Purohit R. Use of long term molecular dynamics simulation in predicting cancer associated SNPs. PLoS Comput Biol. 2014; 10(4):e1003318

12. Zhang L, Zhu Z, Wu H, Wang K. Association between SNP309 and del1518 polymorphism in MDM2 homologue and esophageal squamous cell carcinoma risk in Chinese population of Shandong Province. Ann Clin Lab Sci. 2015;45(4):433-437.

13. Chen X, Sturgis EM, Lei D, Dahlstrom K, Wei Q, Li G. Human papillomavirus seropositivity synergizes with MDM2 variants to increase the risk of oral squamous cell carcinoma. Cancer Res. 2010;70(18): 7199-7208.

14. Xie L, Sun Y, Chen T, et al. Association between MDM2 SNP309 T > G polymorphism and the risk of bladder cancer: new data in a Chinese population and an updated meta-analysis. Onco Targets Ther. 2015;8: 3679-3690.

15. Qiu M, Liu Y, Yu X, et al. Interaction between p53 codon 72 and MDM2 $309 \mathrm{~T}>\mathrm{G}$ polymorphisms and the risk of hepatocellular carcinoma. Tumour Biol. 2016;37(3):3863-3870.

16. McGraw KL, Cluzeau T, Sallman DA, et al. TP53 and MDM2 single nucleotide polymorphisms influence survival in non-del $(5 q)$ myelodysplastic syndromes. Oncotarget. 2015;6(33):34437-34445.

17. He X, Chen P, Yang K, et al. Association of MDM2 polymorphism with risk and prognosis of leukemia: a meta-analysis. Acta Haematol. 2015; 133(4):365-371.

18. Misra C, Majumder M, Bajaj S, Ghosh S, Roy B, Roychoudhury S. Polymorphisms at p53, p73, and MDM2 loci modulate the risk of tobacco associated leukoplakia and oral cancer. Mol Carcinog. 2009;48(9): 790-800.

19. Ma K, Cao B, Guo M. The detective, prognostic, and predictive value of DNA methylation in human esophageal squamous cell carcinoma. Clin Epigenetics. 2016;8:43. 
20. Kumar S, Shah JP, Bryant CS, et al. Prognostic significance of keratinization in squamous cell cancer of uterine cervix: a population based study. Arch Gynecol Obstet. 2009;280(1):25-32.

21. Marur S, Forastiere AA. Head and neck squamous cell carcinoma: update on epidemiology, diagnosis, and treatment. Mayo Clin Proc. 2016;91(3): 386-396.

22. Stratigos A, Garbe C, Lebbe C, et al. Diagnosis and treatment of invasive squamous cell carcinoma of the skin: European consensus-based interdisciplinary guideline. Eur J Cancer. 2015;51(14):1989-2007.

23. Derman BA, Mileham KF, Bonomi PD, Batus M, Fidler MJ. Treatment of advanced squamous cell carcinoma of the lung: a review. Transl Lung Cancer Res. 2015;4(5):524-532.

24. Zhou J, Liu F, Zhang D, et al. Significance of MDM2-309 polymorphisms and induced corresponding plasma MDM2 levels in susceptibility to laryngeal squamous cell carcinoma. DNA Cell Biol. 2014;33(2):88-94.

25. Hamid S, Yang YH, Peng KN, et al. MDM2 SNP309 does not confer an increased risk to oral squamous cell carcinoma but may modulate the age of disease onset. Oral Oncol. 2009;45(6):496-500.

26. Liu J, Zheng Y, Lei D, et al. MDM2 309T $>$ G polymorphism and risk of squamous cell carcinomas of head and neck: a meta-analysis. Asian Pac J Cancer Prev. 2011;12(8):1899-1903.

27. Xie JL, Yang JL, Liu DS, Xie YG, Ji P. Impact of MDM2 single nucleotide polymorphism on oral squamous cell carcinoma risk. Cell Biochem Biophys. 2015;71(2):993-998.

28. Chen B, Xiong MM, Meng XL. Current evidence on the relationship between murine double minute $2 \mathrm{~T} 309 \mathrm{G}$ polymorphism and esophageal cancer susceptibility. Dis Esophagus. 2015;28(6):593-601.

29. Yang J, Liu B, Li W, et al. Association of $\mathrm{p} 53$ and MDM2 polymorphisms with risk of human papillomavirus (HPV)-related esophageal squamous cell carcinoma (ESCC). Cancer Epidemiol. 2013;37(5):629-633.

30. Er LM, Zhang LW, Nie WW, et al. Relevance of MDM2 polymorphisms with esophageal squamous cell carcinoma, gastric adenocarcinoma and double primary cancers in esophagus and stomach. Zhonghua Yu Fang Yi Хие Ниi. 2012;39(13):3342-3344.

31. Alhopuro P, Ylisaukko-Oja SK, Koskinen WJ, et al. The MDM2 promoter polymorphism SNP309T--> G and the risk of uterine leiomyosarcoma, colorectal cancer, and squamous cell carcinoma of the head and neck. J Med Genet. 2005;42(9):694-698.

32. Roszak A, Misztal M, Sowińska A, Jagodziński PP. Murine doubleminute 2 homolog single nucleotide polymorphisms 285 and 309 in cervical carcinogenesis. Mol Diagn Ther. 2015;19(4):235-244.

33. Hong Y, Miao X, Zhang X, et al. The role of P53 and MDM2 polymorphisms in the risk of esophageal squamous cell carcinoma. Cancer Res. 2005;65(20):9582-9587.

34. Liu G, Wheatley-Price P, Zhou W, et al. Genetic polymorphisms of MDM2, cumulative cigarette smoking and nonsmall cell lung cancer risk. Int J Cancer. 2008;122(4):915-918.

35. Tu HF, Chen HW, Kao SY, Lin SC, Liu CJ, Chang KW. MDM2 SNP 309 and p53 codon 72 polymorphisms are associated with the outcome of oral carcinoma patients receiving postoperative irradiation. Radiother Oncol. 2008;87(2):243-252.

36. Park SH, Choi JE, Kim EJ, et al. MDM2 309T $>$ G polymorphism and risk of lung cancer in a Korean population. Lung Cancer. 2006;54(1): 19-24.

37. Nakashima M, Kondo S, Shimizu Y, et al. Impact of MDM2 single nucleotide polymorphism on tumor onset in head and neck squamous cell carcinoma. Acta Otolaryngol. 2008;128(7):808-813.

OncoTargets and Therapy

\section{Publish your work in this journal}

OncoTargets and Therapy is an international, peer-reviewed, open access journal focusing on the pathological basis of all cancers, potential targets for therapy and treatment protocols employed to improve the management of cancer patients. The journal also focuses on the impact of management programs and new therapeutic agents and protocols on
38. Loginov VI, Atkarskaia MV, Burdennyĭ AM, et al. [Association of Arg72Pro of TP53 and T309G of MDM2 genes polymorphisms with non-small-cell lung cancer in Russians of the Moscow region]. Mol Biol (Mosk). 2014;48(1):52-57. Russian.

39. Jiang P, Liu JW, Li W, Zeng XX, Tang JX. Correlation between MDM2 gene SNP309 polymorphisms and cervical cancer. Clin Oncol Cancer Res. 2011;38(1):1-4.

40. Huang SF, Chen IH, Liao CT, Wang HM, Liou SH, Hsieh LL. Combined effects of MDM2 SNP 309 and p53 mutation on oral squamous cell carcinomas associated with areca quid chewing. Oral Oncol. 2009;45(1): $16-22$.

41. Yu H, Huang YJ, Liu Z, et al. Effects of MDM2 promoter polymorphisms and p53 codon 72 polymorphism on risk and age at onset of squamous cell carcinoma of the head and neck. Mol Carcinog. 2011;50(9):697-706.

42. Ma J, Zhang J, Ning T, Chen Z, Xu C. Association of genetic polymorphisms in MDM2, PTEN and P53 with risk of esophageal squamous cell carcinoma. J Hum Genet. 2012;57(4):261-264.

43. Cao YY, Zhang XF, Guo W, Wang R, Hui Ge H, Zhang JH. Association of the MDM2 polymorphisms with susceptibility of esophageal squamous cell carcinoma and that of gastric cardiac adenocarcinoma. Tumor. 2007;27(8):628-632.

44. Kohno T, Kunitoh H, Mimaki S, et al. Contribution of the TP53, OGG1, CHRNA3, and HLA-DQA1 genes to the risk for lung squamous cell carcinoma. J Thorac Oncol. 2011;6(4):813-817.

45. Singhal P, Hussain S, Thakur N, et al. Association of MDM2 and $\mathrm{p} 53$ polymorphisms with the advancement of cervical carcinoma. DNA Cell Biol. 2013;32(1):19-27.

46. Li R, Zhang L, Liu Z, et al. Correlation of MDM2 gene polymorphisms and risk of esophageal squamous cell carcinoma in south-west Shandong Han nationality. J Xinxiang Med Coll. 2011;28(4):437-439.

47. Nan H, Qureshi AA, Hunter DJ, Han J. A functional SNP in the MDM2 promoter, pigmentary phenotypes, and risk of skin cancer. Cancer Causes Control. 2009;20(2):171-179.

48. Zhang XM, Miao XP, Guo YL, et al. Genetic polymorphisms in cell cycle regulatory genes MDM2 and TP53 are associated with susceptibility to lung cancer. Hum Mutat. 2006;27(1):110-117.

49. Bond GL, Hu W, Levine A. A single nucleotide polymorphism in the MDM2 gene: from a molecular and cellular explanation to clinical effect. Cancer Res. 2005;65(13):5481-5484.

50. Hu Z, Jin G, Wang L, Chen F, Wang X, Shen H. MDM2 promoter polymorphism SNP309 contributes to tumor susceptibility: evidence from 21 case-control studies. Cancer Epidemiol Biomarkers Prev. 2007; 16(12):2717-2723

51. Chen B, Cao L, Hu KW, Zhang JW, Meng XL, Xiong MM. MDM2 SNP309 is an ethnicity-dependent risk factor for digestive tract cancers. Tumour Biol. 2014;35(4):3431-3438.

52. Liu G, Cescon DW, Zhai R, et al. p53 Arg72Pro, MDM2 T309G and CCND1 G870A polymorphisms are not associated with susceptibility to esophageal adenocarcinoma. Dis Esophagus. 2010;23(1):36-39.

53. Chen JY, Yang H, Wen J, et al. Association between positive murine double minute 2 expression and clinicopathological characteristics of esophageal squamous cell carcinoma: a meta-analysis. Dis Esophagus. Epub 2015 Apr 15.

54. Vlatković N, El-Fert A, Devling T, et al. Loss of MTBP expression is associated with reduced survival in a biomarker-defined subset of patients with squamous cell carcinoma of the head and neck. Cancer. 2011; 117(13):2939-2950.

\section{Dovepress}

patient perspectives such as quality of life, adherence and satisfaction. The manuscript management system is completely online and includes a very quick and fair peer-review system, which is all easy to use. Visit http://www.dovepress.com/testimonials.php to read real quotes from published authors. 